\title{
ASPECTOS DA CONTRATAÇÃO INTERNACIONAL
}

\author{
Irineu Strenger \\ Professor Titular da Faculdade de Direito da \\ Universidade de São Paulo
}

\begin{abstract}
Resumo:
Este artigo coloca, em relevo, aspectos relevantes dos contratos internacionais do comércio, acentuando seu autor que, não-obstante as divergências da doutrina, se encontram fórmulas tonicamente conclusivas de cooperação, colocando-se, nessa trilha inovadora, relações negociais entre Estado e particulares, confirmadas na figura inquestionável do Estado-comerciante, admitida em todos os sistemas de Direito contemporâneo.
\end{abstract}

\begin{abstract}
:
The present work brings a highlight to relevant aspects of international trade contracts, while the author gives special focus to the fact that, notwithstanding the doctrine's different approaches, technically conclusive formulae of cooperation are in use. In this new light one can find the trading relations between the merchant State and private companies or parties, largely accepted within contemporary Law systems.
\end{abstract}

Unitermos: contrato internacional de comércio; noção do contrato internacional.

\section{Peculiaridades do Contrato Internacional do Comércio}

Em nossos dias, o comércio internacional é fato incontestável, e nenhum praticante dessa atividade pode dispensar-se de examinar, em profundidade, as exigências profissionais dessa área negocial.

A abrangência do comércio internacional, nos tempos atuais, é de tal envergadura, que suplanta, inclusive, as tradicionais divergências ideológicas entre o Leste e o Oeste, criando novas modalidades de convivência, e, a despeito das diversificações das sistemáticas jurídicas, são encontradas fórmulas tecnicamente conciliáveis de cooperação. 
Colocam-se, ainda, nessa mesma trilha inovadora, as relações negociais entre o Estado e os particulares, hoje confirmadas na figura do Estado comerciante, e indeclinavelmente institucionalizado.

O Direito do Comércio Internacional, ou a nova lex mercatoria, traduz realidade composta de dados e elementos peculiares, evidenciantes de estruturas distintas daquelas que sustentam os Direitos Comerciais Internos, cujo papel se circunscreve ao âmbito territorial, sem que suas projeções possam significar mais do que a garantia da ordem pública.

Além disso, a intensificação das soluções arbitrais optadas leva à generação de jurisdições especializadas, que têm, largamente, transposto os limites dos Judiciários estatais, para com estes ficarem ligadas, apenas no que tange a eventuais legitimações dos decisórios arbitrais, à busca da titularidade, com eficácia executória.

O comércio internacional tem, irrefutavelmente, características próprias e não prescinde dos usos e costumes, que são suas principais formas de expressão, colocadas no plano do Direito. E o seu principal instrumento de ação exercita-se e efetiva-se nos contratos internacionais que, dia-a-dia, aumentam seu repertório textual, criando fórmulas possibilitantes de dar fundamento, garantia, segurança e certeza aos negócios, sempre necessitados de sustentação jurídica.

$\grave{A}$ diferença dos contratos tradicionais, os internacionais identificam-se com as exigências nascidas do caráter setorizante e profissionalizante dos negociantes transnacionais, cujas relações exigem soluções complexas, geralmente traduzidas em técnicas próprias, e correlatas às peculiaridades do comércio envolvido.

Tarefa das mais árduas será a procura dos conceitos no plano do comércio internacional, pela incipiência de suas formas de expressão.

O comércio internacional, identificado com a lex mercatoria, explica-se como trajetória cheia de percalços, pela alta fecundidade de seus agentes reveladores, os quais põem, inevitavelmente, em constante interação, os fatores da prática e da teoria.

Tentar conceituações abrangentes, em relação aos contratos do comércio internacional, seria lançar-se em densa floresta, na qual as picadas continuam sendo abertas, sem que o ponto de chegada tenha sido determinado.

Entretanto, não se pode deixar de esboçar as diversas situações que conduzem ao processo de formação dos contratos, e sua conclusão, para permitir aos iniciantes e estudiosos dessa nascente disciplina jurídica, visão orientada de seus principais problemas. 
Deste modo, a conceituação dos contratos internacionais do comércio parte dos pressupostos fáticos, encaminhando-se, na medida do possível, para a sintetização, tecnicamente assimilada, de seus principais elementos.

Essa sintetização, por vezes, é extravasante de sua própria significação lógica, porque não existe, ainda, a possibilidade de reunir, topicamente, todas as circunstâncias que envolvem a problemática dos contratos internacionais do comércio.

O que não se tem mais dúvida, porém, é de que os contratos internacionais do comércio, cada vez mais, isolam-se das figurações doutrinárias clássicas, e válidas, segundo as tradições dos Direitos nacionais, cuja universalização se expressa em meras identidades, mas que não servem para satisfazer as exigências peculiares do comércio internacional.

Concebida a matéria contratual, pelo prisma do Direito nacional, podese fixar a impressão de que, metodologicamente, a distinção entre os denominados contratos internos e contratos internacionais depende unicamente de fatores geográficos ou espaciais.

Muitos autores, de tendências chauvinistas, entendem que, meramente, um contrato é internacional, quando coloca na relação jurídica elementos nacionais ou estrangeiros, seja pela via das conexões domiciliares e suas ramificações, seja pela via da nacionalidade, quer da pessoa natural, como jurídica.

Entretanto, para aqueles que estão familiarizados com as atividades e operações do comércio internacional, essa visão, embora presentes algumas conotações válidas, não satisfaz tecnicamente a compreensão do problema.

$\mathrm{Na}$ verdade, o contrato internacional é conseqüência do intercâmbio entre Estados e pessoas, no sentido amplo, cujas características são diversificadoras dos mecanismos conhecidos e usualmente utilizados pelos comerciantes circunscritos em um único território, e os transterritoriais.

Esses acenos doutrinários não significam, porém, que se queira, ou mesmo que se possa, trocar um extremo por outro. Não se reivindica a autonomia do Direito do Comércio Internacional, como se fora uma descoberta sistemática, capaz de mostrar contornos próprios dessa recente disciplina, demonstrativos de que, entre o comércio interno e internacional, não exista interpenetração.

Se, cautelosamente, se adota essa perspectiva, para não incorrer em elaboração artificiosa, não é menos certo e incontestável que o Direito do Comércio Internacional se assenta em pressupostos próprios e inconfundíveis.

As origens consuetudinárias do comércio internacional explicam a 
riqueza de sua criatividade, e não é sem razão que autores como Giorgio Sacerdoti, François Rigaud, Bertold Goldman, Yon Loussouarn, Tudor Popescu, René David, Philippe Kahn, Jean-Denis Bredin, Pierre Lalive, Henry Lesguillons e muitos outros salientam as peculiaridades do comércio internacional, gerando Direito próprio e acrescentando, progressivamente, dados nascidos da prática e defluentes da setorização que identifica as atividades negociais do mundo moderno.

O comércio internacional, exatamente por compor-se de especializações e subespecializações, submete-se a exigências instrumentais, que evoluem ao sabor dos pactos e convenções, cuja natureza reflete necessidades concretas, nascidas de uma criatividade impositiva.

Os contratos internacionais são o motor, no sentido estrito, do comércio internacional e, em sentido amplo, das relações internacionais, em todos os seus matizes.

A experiência, contudo, demonstra-nos que o contratualista não satisfaz necessariamente aos requisitos do contratualismo internacional.

A taxinomia dos contratos de Direito Interno pode apresentar coincidências monilatísticas, mas não identificáveis na essencialidade com os modos dos contratos internacionais.

Como ensina Bruno Oppetit, os contratos internacionais envolvem-se em uma atmosfera política e econômica, de maneira extremamente sensível às constantes mutações geradoras de conflitos e incertezas.

Dir-se-á que as mutações políticas e econômicas ocorrem em todos os planos, de maneira que essa nota não distingue os contratos internacionais dos internos.

A exatidão dessa observação colide, porém, com um plus, que é a complexidade envolvente das relações internacionais, levando, inevitavelmente, a enfrentar as repercussões de sistemas e direitos diferenciados pela multiplicidade de elementos conflitantes, e, por conseguinte, exigentes de instrumentos harmonizadores não necessitados na esfera nacional.

Procurando sempre evitar radicalismos, impõe-se consignar alguns traços comuns entre os contratos internos e internacionais, que podem ser colhidos na dogmática das obrigações e nos princípios gerais sobre o negócio jurídico.

As normas do Direito obrigacional são inevitavelmente aplicáveis às relações jurídicas emergentes da atividade mercantil, com algumas modificações. Tais modificações justificam-se pela necessidade de adaptar a ordem jurídica positiva à especialidade técnica da atividade econômico-mercantil. Esse é um aspecto confluente do Direito do Comércio Internacional e Interno, porquanto ambos têm por objeto a 
sistematização de técnicas jurídicas adequadas às operações de transformação de circulação de bens ou de serviços no mercado.

As necessidades da economia moderna, impondo a produção em série para atendimento das exigências do consumo em massa, acarretam a ampliação e o aprimoramento do mercado, gerando novas técnicas negociais, que se consubstanciam em normas integradas, em novos institutos jurídico-mercantis.

As técnicas de realização das operações comerciais, praticadas com maior freqüência e simplicidade, mediante amplo recurso ao crédito, tornam indispensável a adaptação das normas do Direito comum às características especiais dos negócios mercantis.

Como bem assinala José Luís Siqueiros: “A contratação, isto é, o acordo bilateral, pode produzir-se nos âmbitos interno e internacional. Quando os elementos constitutivos do contrato (partes, objeto, lugar onde se pactua a obrigação, lugar onde deverá surtir seus efeitos) se originam e se realizam dentro dos limites geográficopolíticos de um único pais, estamos situados no âmbito interno das obrigações. Inversamente, quando as partes contratantes tenham nacionalidades diversas ou domicilio em paises distintos, quando a mercadoria ou o serviço objeto da obrigação seja entregue ou seja prestado além-fronteiras, ou quando os lugares de celebração e execução das obrigações contratuais tampouco coincidam, estarem no âmbito dos contratos internacionais"

"Do ponto de vista da lei aplicável aos efeitos contratuais, a diferença é evidente. Enquanto no primeiro caso (âmbito interno) o Direito Internacional regulará todos os aspectos relativos à formação e conseqüências do negócio jurídico, na segunda hipótese (âmbito internacional), existe a possibilidade de que diversas legislações pretendam exercer controle, tal como a lei nacional das partes contratantes, a lei do domicílio, a lei de celebração do contrato, a lei do lugar de sua execução etc. Dito em outras palavras, o contrato escapa à regulação do Direito Interno. Na época contemporânea, o desenvolvimento do comércio internacional, em todas as suas formas, a multiplicação e celeridade dos meios de transporte, o incessante intercâmbio de mercadorias e serviços, é um fato notório"

"A atividade comercial transcende as fronteiras internacionais e acarreta a interdependência econômica; esse fenômeno percebe-se não-somente nos países em que predomina o sistema de economia de consumo, como também nos de economia planificada. Matérias-primas, componentes e produtos são importados de forma intermitente, e simultaneamente são exportados equipamentos, máquinas e mesmo 
mão-de-obra. Esta corrente incessante de ingresso e saida de mercadorias e serviços tem que se plasmar em acordos e contratos que reciprocamente celebrem importadores e exportadores. Paulatinamente vai sendo tecida rede cada vez mais intrincada"

\section{Noção de Contrato Internacional}

A noção de contrato internacional leva, inevitavelmente, a vinculações mais amplas com os fenômenos jurídicos decorrentes dessa atividade tipicamente relacional.

A figura do Estado comerciante, hoje irrecusável, a proliferação das empresas públicas, nacionais e internacionais, os conglomerados de empresas, a grande penetração dos intercâmbios técnicos, os sistemas de cooperação internacional, os meios de comunicação, e a participação generalizada de pessoas nos mercados nacionais e internacionais, seja a título de investimentos, ou de simples venda e compra, são pressupostos indispensáveis para o raciocínio dos contratos internacionais. Realmente, se quiséssemos compor esses elementos segundo uma taxinomia do Direito, certamente incorreríamos em graves equívocos, pois o comércio internacional tem uma forte atração pelo regime da lex mercadoria, e esta circunstância dá a conotação tipificadora de seu principal instrumento: o contrato internacional.

Philippe Kahn, em recente trabalho, coloca, em termos bem elucidativos, o problema, asseverando: "A interpretação dos contratos internacionais, negligenciada durante muito tempo, começa a atrair atenção. Sem dúvida, o fenômeno não deve ser isolado da retomada do interesse pelo contrato, seja interno ou internacional, manifestado pela doutrina, mas diversas razões parecem ser peculiares ao contrato internacional, tanto de ordem teórica quanto prática"

Durante o extraordinário crescimento do comércio internacional de 1950 a 1970, os esforços foram dirigidos para a estruturação juridica de numerosas inovações da prática, tais como os contratos turn key (clé en main), os contratos de transferência de tecnologia, os contratos de cooperação industrial, os contratos associativos (empresas conjuntas), os contratos de financiamento (contratos de euro-obligation ou de eurocrédit). Da mesma forma, muitos esforços foram consagrados ao aperfeiçoamento do órgão jurisdicional privado que constitui a arbitragem. A teoria do contrato internacional foi dominada pela comparação dos méritos respectivos do método conflitual e do método de Direito Material e, sobretudo, pelo questionamento a respeito do pluralismo de ordenamentos jurídicos e sobre a existência de uma ordem jurídica privativa dos agentes do comércio internacional (lex mercatoria). As necessidades de estruturar a lex 
mercatoria, estabelecendo os princípios de funcionamento do sistema, fizeram passar para plano secundário os problemas de interpretação. Mas, agora, a construção parece suficientemente coerente para que seja testada, passando pelo crivo da crítica que constituem os problemas cotidianos, tanto mais que esses problemas se multiplicam.

$\mathrm{Na}$ verdade, a crise que atingiu o sistema mundial, agravada a partir de 1974, tornou problemática a execução de numerosos contratos celebrados no otimismo do crescimento e ainda em fase de cumprimento. Os contratantes tornaram-se muito mais atentos à interpretação dos compromissos assumidos. Um sistema em crise é menos generoso. Basta mencionar aqui um problema, o da revisão dos contratos, que não é o único.

O atraso das especulações sobre a interpretação também era devido à falta de documentos. O sigilo, cercando as sentenças arbitrais, levado ao extremo, se não ao excesso, constituiu durante muito tempo obstáculo a qualquer tentativa de estudo sério. Se o conhecimento dos contratos e a pesquisa junto aos agentes econômicos tinham sido suficientes para elaborar as grandes linhas de lex mercatoria em seu aspecto dinâmico, a interpretação de um contrato internacional é, muitas vezes, contenciosa, mesmo se não integralmente absorvível pelo contencioso, para que a ignorância das sentenças arbitrais não seja um obstáculo dirimente. Este obstáculo está em larga medida superado, a partir do momento em que as grandes instituições arbitrais começaram a se mostrar menos reservadas no que concerne à publicação de sentenças sob a forma de excertos, com certeza discretos no que se refere às partes mas fornecendo informações essenciais sobre as soluções alcançadas.

Nem tudo na interpretação dos contratos internacionais é original, e os problemas gerais de interpretạ̧ão acham-se neste caso, como em outros, com a mesma utilização dos elementos de raciocínio e de lógica que levam a determinar o sentido das palavras e frases que constituem as normas jurídicas. Não teria interesse, excetuado um caso de aplicação, abordar a interpretação sob esse ângulo.

Por outro lado, os contratos internacionais, apresentam especificidades que justificam tratamento peculiar.

O meió internacional, mesmo restrito aos operadores e agentes econômicos, é muito disperso. Uma das primeiras preocupações dos redatores de contratos internacionais é tentar reduzir, não podendo eliminar, completamente, as contradições de comunicação, de conceitualização ou de articulação engendradas por essa dispersão. Mas, cumprida essa primeira missão, ainda é preciso determinar, no âmbito de uma comunidade, cuja especialidade é restrita às operações do comércio 
internacional (em sentido amplo), segundo quais princípios sua coesão pode ser assegurada, seus documentos analisados e tornados eficazes.

Os contratos internacionais são, por conseguinte, fruto de uma multiplicidade de fatores, envolvendo métodos e sistemas interdisciplinares, inspirados na economia, na política, no comércio exterior, nas ciências sociais e, com muitos frutos colhidos nas relações internacionais, de toda índole.

O contrato internacional pode ser comparado a uma rosácea, na qual intervém as diversas nuances coloridas, que lhe dão a característica distintiva de outros congêneres artísticos. Essa constatação pode ser colhida no próprio mecanismo operacional dos contratos internacionais, geralmente dissociados dos impositivos legais, que intitular os regimes jurídicos internos. Mesmo o conceito de regionalização, quando utilizado para setorizar o comércio internacional, não se confunde com a idéia de localismo, porquanto essa divisão é menos de caráter geográfico do que conseqüência das peculiaridades do mercado.

Todas essa considerações mostram que o contrato internacional, atualmente, ultrapassa o estágio doutrinário que assim o considerava a partir da estraneidade ou-não das partes, como bem o demostra Pierre Lalive, ao acentuar: "Em Direito Internacional Privado, a qualificação internacional, aplicada a uma determinada situação, tende a ser empregada em sentido muito amplo, quando se reporta, por aspectos prima facie significativos, a mais de um ordenamento juridico. Nesse sentido, pôde ser definido como internacional, o contrato, cujos elementos (que devemos subentender, pertinentes) não estão localizados no mesmo território. A insuficiência de uma tal definição salta aos olhos: a dificuldade não é resolvida, mas reportada, e quase tudo ainda fica para ser feito, uma vez que será precioso definir quais os elementos pertinentes ou significativos no caso. Supô-los repartidos entre dois paises, no mínimo, será preciso, e além disso, decidir se a internacionalidade que dai resulta é bastante forte para provocar, no tocante aos problemas suscitados, uma diferença de regime com relação ao contrato interno"

As opiniões até aqui elencadas, sem exaurir a matéria, são, entretanto, suficientes à condução da idéia de que os contratos internacionais, figurativos de rica fenomenologia jurídica, aparelham-se a cada passo, para permitir a construção de uma teoria geral concatenada.

Trata-se de processo relativamente lento, porque o método indutivo, único capaz de fecundar a globalização dos conceitos, impõe o esmiuçamento das particularidades, que, no comércio internacional, plenificam as relações negociais. 
Algumas premissas podem, entretanto, ser enunciadas, em termos proposionais, a saber:

1. Os contratos internacionais são, casualmente, identificáveis. Significa que os substratos fáticos dos contratos internacionais são formados de dados extremamente sensíveis a todas as atividades operacionais do comércio internacional. Depreende-se dessa convicção que os contratos internacionais não são uma especialização do Direito, mas uma profissionalização das atividades comerciais. Vale dizer que os contratos internacionais refletem a vontade negocial, com preponderância sobre os estereótipos jurídicos.

2. Os contratos internacionais são os únicos instrumentos de ação para o comércio internacional, sem vínculos com esquemas legais geograficamente circunscritos. Embora os contratos internacionais não se exauram juridicamente nos seus próprios termos, a eficácia convencional remanesce como fulcro de sua execução.

3. Os contratos internacionais transcendem os limites estritos do Direito, para se converter em instrumento multidisciplinário, em forma de sintetizações oriundas de um processo de complementariedade.

4. Os contratos internacionais não são meros veículos convencionais, mas fórmulas de elaborações conjunturais, que permitem elastificação do objeto em plano de alta diversificação, relativamente a bens usualmente chamados de visíveis e invisíveis.

5. Os contratos internacionais fundamentam-se em sistemas principiológicos mais do que legais, como decorre da noção da lex mercatoria.

\section{Autonomia técnica dos Contratos Internacionais}

A autonomia técnica dos contratos internacionais adquire progressivamente viabilidade afirmativa, principalmente a partir da consolidação da teoria da lex mercatoria, e, sobretudo, pela criatividade decorrente das operações do comércio internacional, desenvolvidas a latere dos Direitos nacionais, e rapidamente aceita, sem discussão. Válida, igualmente, a idéia de que os praticantes do comércio internacional constituem uma comunidade, que procura elaborar as suas próprias regras.

Como conseqüência inevitável de todos esses fatores, esboça-se uma tipologia de operações, em processo contínuo de enriquecimento, determinando o dinamismo do contrato internacional, cuja evidência é difícil discutir.

É preciso também salientar que, em nossos dias, os operadores do mercado internacional formam meio suficientemente homogêneo para que as 
solidariedades profissionais se façam sentir, exprimindo as necessidades e soluções jurídicas de que são carentes, de modo homogêneo e adequado.

Philippe Kahn, abordando a matéria, segundo a sistemática francesa, explica: "A evolução mais importante dos últimos quinze anos na prática francesa dos contratos internacionais acha-se no enriquecimento considerável de sua tipologia. Não existe um contrato internacional, mas um grande número de figuras contratuais, ou mesmo de complexos contratuais, em número crescente, e em decorrência de situações diversificadas. Parece-nos que a heterogeneidade e o numero dos contratos econômicos internacionais constituem um dos problemas mais delicados que devem ser enfrentados atualmente pela teoria da lex mercatoria, tanto no que concerne a seu conteúdo, quanto no que concerne à sua abrangência"

"A teoria da lex mercatoria repousa sobre a constatação de que práticas por intermédio dos contratos conseguiram, em larga medida, unificar o regime juridico da venda internacional e das operações anexas ou complementares. Ora, a prática francesa, bem como a da maioria dos paises, mostrou a necessidade de se fazer distinção entre, pelo menos, três ramos: contratos de troca (contrats d'échange), contratos de produção (contrats de production), contratos de fornecimento (contrasts d'approvisionnement)."

Se considerarmos a técnica como meio apropriado e insubstituível para a realização de determinado desiderato, com utilização de instrumentalidade própria, teremos, no caso dos contratos internacionais do comércio, a configuração dessa circunstância.

Aqueles que atentaram para os pressupostos da teoria geral dos contratos internacionais terão percebido que essa modalidade convencional traz recursos individualizados em fontes materiais e formais distintas da tradição clássica.

A primeira razão que ampara essa afirmativa é a, propriamente dita, oriunda do progresso científico e, portanto, temporalmente recente, com inovações que nossos ancestrais nem sequer poderiam imaginar. Assim, a técnica dos contratos internacionais obedece estritamente os parâmetros da técnica geral. Vários exemplos o confirmam: containers, paletizadores, sistemas rô-rô nos transportes marítimos, e todas as reformulações criadas pelo comércio plurissetorizado.

A segunda razão prende-se às novas versões empresariais, não-só o regime consorcial, como principalmente a implantação do grupamento horizontal de empresas e o sistema de cooperação individualizada em contratos sui generis.

Outro fator tecnicizante dos contratos prende-se à duração prolongada 
dos grandes empreendimentos e à participação multinacional das empresas, forçando a escolha de direitos alienígenas e a implantação de regimes jurídicos autônomos.

Finalmente, justifica a conviç̧ão autonomista das técnicas do contrato internacional, a crescente implementação dos negócios entre particulares e Estados, motivando não-só a formulação adequada e original das cláusulas convencionais.

As passagens doutrinárias e algumas fixações teóricas de efeitos determinadores dos contratos internacionais levam, naturalmente, à enunciação das características identificadoras das formalizações do comércio internacional, através das diversas modalidades de ajustes negociais.

Antes de se chegar a um esboço de classificação, pertine esclarecer que o vocábulo caracteristicas é empregado com o sentido de entrever, nos contratos internacionais, certas notas distintivas, não-só de estrutura, como de sistema.

Ao estudar esse assunto, verificamos que nos contratos internacionais ocorre um processo inexoravelmente desenvolvimentista, que, continuamente, gera a eclosão de novas cláusulas, sempre destinadas a satisfazer as exigências do comércio internacional, desempenhando papel de extrema singularidade, quanto às diferentes instituições que abrange.

Sem dúvida, existem regras nascidas das práticas internacionais, compostas pelos usos profissionais e princípios gerais do Direito, com encaminhamentos inevitáveis de adaptação à vida própria do comércio internacional. E mesmo que se admita a forma normativa dos Direitos estatais, verifica-se que, no plano internacional, em matéria de lei aplicável ao contrato, interferem disposições supletivas e disposições imperativas, sendo de se notar que as primeiras, periodicamente, revigorizam-se, através de regulamentações associativas, inclusive através da criatividade individualizada pelas especializações do comércio.

Fenômeno que deve ser especialmente realçado é o da força crescente do princípio da autonomia da vontade, cuja extensão já avança à área dos países de economia planificada. E hoje parece incontestável que a noção de contrato, estimulada por essa influência, sofreu notáveis evoluções.

Em verdade, a prática jurídica internacional repousa grandemente e até com certa obstinação, na lex voluntatis', pois, perdendo esse princípio, aquele caráter tradicional de ajuste de vontades dos indivíduos transformou-se numa expressão de natureza comunitária, através dos regulamentos e das leis-tipo, quase sempre emanadas de órgãos e entidades não-governamentais.

Se tomarmos o conceito de contrato segundo os cânones tradicionais, 
veremos que os juristas distinguem entre os contratos clássicos - aqueles a título oneroso ou gratuito, desinteressados, sinalagmáticos, unilaterais, consensuais, reais, solenes, etc. - e procuram definir suas condições de formação e de validade, através do consentimento, objeto, causa e seus efeitos entre as partes, principalmente as relações entre contratantes e terceiros.

Essas visões, sedimentadas em certa acomodação doutrinária, não se coadunam com a natureza e características dos contratos internacionais, que repousam mais na execução do que nos outros elementos formadores do contrato, para o fim de se deduzir sua real contextura jurídica.

Um autor já disse, habilmente, que quase não há diferença entre um contrato e o amor: no começo tudo é perfeito, mas somente o uso revelará se o dia seguinte será de choro ou alegrias.

Do ponto de vista prático, pode-se dizer que um contrato internacional de comércio é a constatação de uma situação e a definição de um quadro de ação. É a expressão a priori de uma situação que deve evoluir em um lapso de tempo, em função de decisões voluntárias, ou de causas involuntárias, das quais é preciso ter nítida consciência.

O contrato internacional é, nessas circunstâncias, um elemento dinâmico e não um monumento jurídico.

Em lugar de, figurativamente, abrigá-lo num cofre forte depois da assinatura, e somente aplicá-lo se houver um litígio, quando não há uma exata recordação dos termos que contém, é preciso ter o contrato internacional como um instrumento de trabalho, que permite verificar, periodicamente, entre os cosignatários, se as circunstâncias nas quais foi concluído continuam as mesmas. Daí decorre a necessidade de um preâmbulo, descrevendo essa circunstância. Se, a despeito de alterações nas circunstâncias, as partes desejam continuar sua colaboração, um aditivo ou complementação no texto original será suficiente para descrever a nova situação, ou então, até mesmo, limitar e suspender a atividade decorrente do ajuste contratual.

Se concebermos essas colocações como pretipificadoras, podemos dizer que, no plano internacional, é possível distinguir, no âmbito do contrato, dois modos: os fundamentais e os operacionais.

Os primeiros engajam a emplesa numa estrutura política. A parte fundamental é uma espécie de utensilio de trabalho dos dirigentes e faz parte dos elementos de gestão, como ocorre, p. ex., na negociação de uma licença de fabricação.

Por seu turno, os modos operacionais inscrevem-se na vida corrente. São mais de caráter estático, concluídos para e pelos serviços funcionais, no quadro de 
suas prerrogativas, sujeitando-se a limitações quanto aos efeitos e aos inconvenientes que possam surgir por ocasião de sua execução, como p. ex., os transportes e as operações bancárias.

\section{Natureza Jurídica dos Contratos Internacionais}

Estudar os contratos internacionais, sem determinar-lhes a natureza jurídica, equivaleria a uma cirurgia sem nenhum conhecimento de anatomia, no caso, anatomia descritiva.

Poder-se-ia, eventualmente indagar em que medida a natureza jurídica dos contratos internacionais limitaria ou ampliaria, do ponto de vista prático, e mesmo teórico, sua operatividade.

A pergunta comporta rápidas considerações. A primeira observação é abrangente e bastaria como justificativa: o contrato internacional do comércio, mais do que elenco de avenças, é verdadeiro complexo de situações oriundas de metodologia interdisciplinar, de natureza vinculante e, especialmente, de caráter abrangente dos múltiplos planos filosófico, político, econômico e social, além dos substratos jurídicos, que informam essas realidades.

Há, evidentemente, um fator comum a todos os contratos que constitui a coluna-mestra para o esclarecimento de sua natureza, que é a negocialidade. Os contratos estão, inevitavelmente, subsumidos à teoria dos atos jurídicos e, nessas circunstâncias, toda construção dogmática deverá admitir esse pressuposto.

Todo processo constitutivo do contrato, compreendendo suas diversas fases formativas e a finalização definida como a execução de seu objeto, revela-se estruturalmente um negócio jurídico.

Não se pode conjecturar a natureza jurídica dos contratos internacionais sem estabelecer uma premissa conceitual, embora genérica, que permita situar o seu centro de gravidade e este é a declaração de vontade, ou ainda, o cumprimento de uma prestação.

Esses dois elementos categoriais conduzem a sua finalidade que será o momento decisivo caracterizável pela constituição, ou pelos efeitos do contrato.

Tratando-se de contratos internacionais, deve acrescer-se, ainda, o elemento espacial, que chamaríamos o âmbito de aplicação das leis, expressão que pode englobar, inclusive, a noção temporal.

A nota específica do ato jurídico, mediante o qual se possa distinguir do fato jurídico, reside no fim prático a que se dirige o processo convencional e que, necessariamente, deve resultar na produção de efeitos jurídicos. 
Compreende-se, contudo, que esse mecanismo não pode ser totalmente uno, nem totalmente diversificado, pela simples razão de que nem sempre pode afetar as mesmas combinações, diante da pluralidade dos atos jurídicos. Paralelamente, os contratos internacionais, como nessa hipótese, os internos, estão sujeitos a uma força motriz, que reside indefectivelmente na vontade humana, liberada por obra do princípio da autonomia da vontade.

Num primeiro passo, pode-se afirmar que a vontade é elemento de grande força impulsiva do ato jurídico contratual, e é exatamente essa nota que permite validar a taxinomia expressa em unilateralidade, bilateralidade e multitateralidade, que, em termos filosofantes, poderíamos chamar pluralização do eu.

A vontade é a criadora do negócio jurídico. Constitui sua essência e o princípio ativo e gerador, de modo que não há negócio quando a vontade está ausente, assim como entendemos que está viciada quando afetada por erro, violência ou dolo.

Nos contratos internacionais, a vontade desempenha nítida função tipificadora, porquanto o comércio internacional, entendido como lex mercatoria que é, impõe, crescentemente, o desaparecimento dos formalismos, fazendo com que se alarguem os limites de ultrapassagem do Direito Positivo, de modo a conquistar a produção de efeitos jurídicos, com penetração incontestada.

Essa perspectiva está consolidada pelo registro das dificuldades de interpretação dos julgadores, nas diversas Justiças, para determinar a natureza e a extensão das consequiências de um negócio jurídico.

A jurisprudência internacional tem dado bom atestado dessa afirmação, pois, freqüentemente, a Declaração do Direito, com base em regras objetivas, tem sido suplantada pela aceitação das vontades individuais dos partícipes do negócio. E este tem sido o encaminhamento de solução dos litígios.

$\mathrm{Na}$ esfera do comércio internacional, a validez e a eficácia negociais têm assentado seu princípio na máxima negotium constitutum sola voluntate (a vontade é criadora do negócio jurídico).

No que concerne à estrutura do contrato internacional, sua determinação faz-se em função dos requisitos de existência e do momento em que o concurso desses requisitos the confere relevância negocial, e sua eficácia deriva da conformidade com as exigências extrínsecas, impostas pelo meio comercial, segundo o critério das setorizações.

Tema capital nessa linha de cogitações é a natureza jurídica da oferta contratual, porquanto deve-se, desde logo, eliminar a oferta desprovida de força 
vinculante. A ausência de compromisso ou poder vinculante relaciona-se com reservas expressas, muito comum nos contratos internacionais, entendidas, quase sempre, segundo o chamado uso circunstancial.

\section{Definição do Contrato Internacional do Comércio}

Os contratos internacionais do comércio têm os seus elementos subjetivo e objetivo e não prescindem da patrimonialidade. Contudo, é preciso acentuar que a internacionalidade dos contratos impõe a pesquisa de outros dados, igualmente constitutivos, concernentes às incursões dos sistemas alienigenas, que se corporificam numa estrutura unificada. Essa orientação, para se chegar a um conceito, admite colocação prévia, que alguns autores chamam de direções inevitáveis dos contratos internacionais, como, p. ex.: a unificação das regras de conflitos de leis, a uniformização do direito substancial, o direito comparado da prática dos contratos intemacionais e a arbitragem internacional. Com efeito, essas perspectivas, em conjunto, cobrem o campo total dos contratos internacionais.

Os ensinamentos do Direito Civil e Comercial, até aqui vigentes, têm obviamente sua validade, pois não se pode deixar de admitir que o contrato, tido como acordo de duas ou mais vontades, deve produzir seus efeitos nos limites fixados pela lei. Contudo, não é menos verdade que os contratos internacionais também apresentam imagem diversa, ao orientar o voluntarismo e o subjetivismo para outras fronteiras: de um lado, os Estados multiplicaram suas leis imperativas para um dirigismo econômico e social, cuja proliferação parece reduzir-se a simples adesão ao ato criador dos contratantes; de outro lado, a complexidade crescente das relações econômicas, o desenvolvimento de novas técnicas, o poder das empresas criaram uma cadeia de relações contratuais, que o Direito estatal não teve possibilidades de prever e que, no espaço internacional, tornou-se impotente para dirigir. E é exatamente nesta zona que se situa o contrato internacional do comércio. O fenômeno contratual contemporâneo está num processo incessante de renovação e diversificação.

Algumas características dos tipos de contratos internacionais devem ser levadas em consideração. São contratos marcados pelo fenômeno de sua duração: longas negociações, execução prolongada, presença de mecanismos de adaptação e de revisão; bem como a tecnicidade dos contratos: cláusulas contratuais relativamente breves em relação às cláusulas técnicas (as primeiras normalmente redigidas de última hora, após longos meses de negociações). As partes têm a preocupação de assegurar a sobrevivência do contrato a todas as vicissitudes, em razão dos consideráveis interesses em jogo, mas 
também de todo o passado e, sobretudo, de todo o futuro de suas relações negociais, que ultrapassa o quadro individual do contrato em tela. As partes, outrossim, não se preocupam somente em salvaguardar suas boas relações recíprocas, mas também de não se isolar do meio negocial em que atuam, por exercício excessivamente detalhista de seus direitos, ou violação demasiado flagrante de suas obrigações. Estas diferentes características provocam enfraquecimento aparente do caráter jurídico, dos contratos em questão: afastamento dos direitos positivos, derrogações importantes a diversos princípios básicos do Direito das Obrigações, repugnância em recorrer à via jurisdicional, mesmo à via arbitral, predominância de aspectos técnicos, psicológicos e comerciais.

Características análogas marcam alguns dos contratos, às vezes chamados econômicos, que, na ordem interna, são celebrados entre os poderes públicos e o setor privado. A reaproximação foi descartada no plano terminológico, mas comparação pode ser feita sobre o plano de fundo.

Estas reflexões sumárias sugerem a idéia de que as características originais, perceptíveis em alguns contratos internacionais, são devidas muito mais ao objeto e à duração do contrato, bem como à natureza das relações gerais entre as partes, do que ao caráter internacional do vínculo contratual. Fenômenos análogos ocorrem no Direito Interno. O contexto internacional, sem dúvida, acentua as características em questão e multiplica suas manifestações, pois a autonomia das partes é aí incontestavelmente maior, e as operações internacionais fornecem oportunidade de celebrar contratos de tal importância, entre tais parceiros, muito mais vezes do que as operações internas.

A verdade incontestável é que, nos últimos quinze anos, os contratos internacionais do comércio se enriqueceram consideravelmente em sua tipologia, a ponto de não se poder falar em um contrato internacional, mas em grande número de figuras contratuais, ou até mesmo complexos contratuais, como já tivemos oportunidade de acentuar.

Estabelecidas essas premissas, e fixada a idéia de que a vida internacional é um fato, cujo envolvimento é o ambiente da empresa atual, pode-se inicialmente configurar como pressuposto que o comércio internacional é o conjunto de operações, com fim lucrativo, que se realiza no mundo, por meio de intercâmbio de bens visíveis (mercadorias), ou de negócios invisíveis (referidos a serviços e transações), que ensejam transferências financeiras em movimento de mercadorias.

A partir dessa concepção, proporíamos a seguinte colocação: um contrato é internacional, desde que seja conectado a normas juridicas emanadas de vários 
Estados, em razão, notadamente, de seu lugar de conclusão ou execução, da localização de seu objeto, da nacionalidade ou do domicilio das partes.

Barthélemy Mercadal e Philippe Janin observam que certas decisões judiciais consideram um contrato internacional desde que coloque em jogo interesses do comércio internacional, mas advertem: "Segundo nosso ponto de vista, essa fórmula não é senão a aplicação do critério mais geral, fundado nos liames do contrato, com vários sistemas jurídicos. Com efeito, dizer que o contrato é internacional, põe em jogo interesses do comércio internacional, significa que é internacional em razão de seu objeto, pois o objeto do contrato não é senão a tradução juridica da operação econômica perseguida pelas partes. Ora, as regras relativas ao objeto fazem parte das normas juridicas, a partir das quais se aprecia o elemento da conexão do contrato, pois o objeto é um dos elementos de validade dos contratos. Contudo, é clara a aplicação de certas regras a um contrato de estraneidade. Assim, o regime da cláusula se refere, coloca em foco os interesses do comércio internacional. Do mesmo modo, o regime do regulamento internacional supõe um duplo movimento de valores que ultrapassa as fronteiras"

Constata-se, nesse itinerário esboçado, que o contrato internacional depende, forçosamente, de um reconhecimento que pode advir de uma decisão judicial ou de ordenamentos jurídicos, e para citar exemplo da última hipótese, menciona-se a recente modificação do "Code de Procédure" francês que, taxativamente, estabelece, no seu art. 1.492 ("Est international l'arbitrage qui met en cause des intérêts du commerce international").

De maneira explícita ou menos explícita, o Direito de cada país encerra regras que possibilitam determinar as condições de reconhecimento da força obrigatória de um contrato internacional.

Assinala-se, ainda, que em toda parte, desperta sólida tendência de liberar os contratantes na determinação do que melhor lhes convier como conteúdo do contrato, sem qualquer vinculação a leis ou direitos eventualmente aplicáveis, sob reserva das regras de ordem pública.

Embora no Brasil não exista no ordenamento positivo de Direito Internacional Privado, institucionalizado, o princípio da autonomia da vontade, os órgãos administrativos disciplinadores do comércio exterior têm transigido, e até mesmo reconhecido cláusulas nesse sentido, inscritas em contratos internacionais, principalmente de transferência de tecnologia.

Não se pode, entretanto, ir ao exagero de admitir a desvinculação dos contratos internacionais de qualquer Direito estatal. Mesmo a França, que se mostra a 
mais liberal dentre os sistemas existentes, tem ressaltado, nas decisões conhecidas, que "tout contrat internacional est nécessairement rattaché à la loi d'un État"

Interpretando esse posicionamento, autores consagrados, como os já citados Mercadal e Janin, advertem que essa fórmula não significa que o contrato deva, obrigatoriamente, ser submedito, pela vontade das partes, à lei interna de um Estado, mas unicamente que, sejam quais forem as estipulações do contrato nesse sentido, o juiz não poderá evitar de apreciar o valor jurídico em função de seu próprio Direito.

Esse princípio é igualmente válido para as convenções internacionais, que definem o regime relativo a certos contratos internacionais, v. g., a Convenção de Haia, de 1955, sobre a lei aplicável às vendas a caráter internacional dos objetos mobiliários corporais, hoje englobada pela Convenção de Viena, 1980, sobre Venda Internacional, ou a certas cláusulas de contratos internacionais como, p. ex., as relativas à arbitragem internacional comercial.

Armados de todas essas informações, podemos ensaiar a seguinte definição de contratos internacionais, sempre lembrando, como raiz metodológica, o princípio do gênero próximo e diferença específica.

São contratos internacionais do comércio todas as manifestações bi ou plurilaterais da vontade livre das partes, objetivando relações patrimoniais ou de serviços, cujos elementos sejam vinculantes de dois ou mais sistemas jurídicos extraterritoriais, pela força do domicílio, nacionalidade, sede principal dos negócios, lugar do contrato, lugar da execução, ou qualquer circunstância que exprima um liame indicativo do Direito aplicável.

\section{Conclusão}

Estes são apenas alguns aspectos da contratualística internacional.

Embora seja matéria nascente já são incontáveis os aportes doutrinários e práticos, sem, contudo, atingir rumos definitivos, graças à imensa se não inesgotável e rica casuística de que se compõe essa área de atividade.

Em nossos dias, já possuímos considerável repositório tipológico dos contratos internacionais e intensa movimentação legislativa, visando à institucionalização dos principais mecanismos do comércio internacional. E, certamente, a cada momento estarão surgindo novas soluções para atender aos continuados reclamos das contingências que envolvem o comércio internacional e o seu principal instrumento operacional: os contratos.

São Paulo, abril de 2001. 
Bibliografia

BREDIN, Jean Denis e Yvon Loussouarn. Droit du Commerce International, Paris, Sirey, 1969.

BROGGINI, Le Modalità d'Esecuzione dei Contratti nel Diritto Internazionale Privato, Freiburg in der Schweiz, 1951.

CREMADES, Bernardo Maria. "Afianzamiento y garantias en el comercio internacional" in Régimen Juridico de las Garantias Contractuales en el Comercio Internacional, Madri, Centro de Estudos Comerciais do Ministério de Economia e Comércio e Câmara Oficial de Comércio e Indústria de Madri, 1981.

KAHN, Philippe. "L'interprétation des contrats internationaux" in Journal du Droit International, v. 108, n. 1, Paris, Eds. Techniques, janeiro-março/81.

La Vente Commerciale Internationale, Paris, Sirey, 1961. Économique International - Stabilité et Évolution, Bruxelas/Paris, Bruylant/Pédone, 1975.

KASSIS, Antoine. Théorie Générale des Usages du Commerce - Droit Comparé, Contrats et Arbitrage Internationaux, «Lex Mercatoria», Paris, Lib. Gén. De Droit et de Jurisprudence, 1984.

SOARES, Guido Fernando Silva. Órgãos das Soluções Extrajudiciais de Litígios, São Paulo, Ed. RT, 1985.

STOUFFLET, J., “L'ouverture du crédit bancaire en Droit International Privé”" in Clunet, 1966.

STOYANOVITCH, K., "La théorie du contrat selon E. B. Packoukanis" in Archive de Philosophie du Droit, t. XIII/89-98, Pais, Sirey, 1968.

OPPETIT, Bruno. "L'adaptation des contrats internationaux aux changements des circonstances: la clause de hardship" in Journal du Droit International, t. IV/ 795/813, Paris, 1974.

Critique de Droit International Privé, v. 62. 
POULLET, Yves. "Les garanties contractuelles dans le commerce international" in Droit et Pratique du Commerce Internacional, t. V, n. 3, Paris, 1979, pp. 387-442.

"Présentation et définition des garanties pratiqués en Europe" in Les Garanties Bancaires dans les Contrats Internationaux, Paris, Fondation pour l'Étude du Droit et des Usages du Commerce Internacional (Feduci), 1981. 